\title{
TIPOS DE ESTACAS E CONCENTRAÇÕES DE AIB NO ENRAIZAMENTO DE ROMÃZEIRA SOB NEBULIZAÇÃO INTERMITENTE
}

\author{
Suely Sayuri Suzuki ${ }^{1}$, Luiz de Souza Corrêa ${ }^{2}$, Aparecida Conceição Boliani ${ }^{2}$, Wagner \\ Massayuki Komessu Suzuki ${ }^{3}$, Gustavo Alves Pereira ${ }^{4}$ \\ ${ }^{1}$ Engenheira Agrônoma, Professora da Rede Estadual de Ensino, Pilar do Sul (SP). \\ ${ }^{2}$ Docente do Departamento de Fitotecnia, Tecnologia de Alimentos e Sócio Economia - Faculdade de \\ Engenharia / UNESP Campus de Ilha Solteira (SP). \\ ${ }^{3}$ Engenheiro Agrônomo, Narandiba (SP). \\ ${ }^{4}$ Docente do Departamento de Ciências Vegetais-Universidade Federal do Semi-Árido, Mossoró (RN).
}

RESUMO: Objetivando verificar o efeito do ácido-3-indolbutírico (IBA) e de três tipos de estacas sobre o enraizamento de estacas de romãzeira (Punica granatum L.). Desenvolveuse experimento, em viveiro com nebulização intermitente, na Fazenda de Ensino Pesquisa e Extensão da Faculdade de Engenharia da UNESP Campus de Ilha Solteira. As estacas foram retiradas da porção mediana de plantas com 5 anos de idade e padronizadas com $15 \mathrm{~cm}$ de comprimento. A seguir procedeu-se o tratamento com ácido indol butírico (IBA) na forma líquida, nas concentrações testemunha, $50 \mathrm{mg} \mathrm{L}^{-1}$ e $100 \mathrm{mg} \mathrm{L}^{-1}$, com imersão de $3 \mathrm{~cm}$ da base das estacas na solução, por 24 horas. Foram realizados mais três tratamentos cujo plantio foi no dia de coleta, perfazendo total de 12 tratamentos. A instalação do experimento foi feita no mês de novembro de 2003 e conduzido até janeiro de 2004 sendo o delineamento experimental adotado foi o de blocos ao acaso, com 3 repetições de 20 estacas por parcela. Após 60 dias avaliaram-se a percentagem de estacas sobreviventes e enraizadas, número de folhas e brotos por estaca, bem como matéria seca de raízes e parte aérea. Nas condições em que o trabalho foi realizado, verificou-se que: o enraizamento de estaca subponteiro foi superior aos tipos ponteiro e ponteiro lateral, tendo apresentado maiores valores de porcentagens de enraizamento $(96,67 \%)$, sobrevivência, número de folhas, massa de matéria seca das raízes e da parte aérea.

Palavras-chave: Punica granatum L. Estaquia. Ácido indolbutírico.

\section{TYPES OF ROOTED AND CONCENTRATIONS OF AIB IN THE ROOTING OF GRENADE UNDER INTERMITTENT NEBULIZAÇÃO}

\begin{abstract}
Objectifying to verify the effect of the indole-3-butyric acid (IBA) and of three types of props on the rooting of grenade props (Punica granatum L.), experiment was developed, in fishery with intermittent mist, the Farm of Education Research and Extension of the College of Engineering of the UNESP Campus of Ilha Solteira. The props had been removed of the medium portion of plants with 5 years of age and standardized with $15 \mathrm{~cm}$ of length. Soon after the treatment with IBA in the liquid form was proceeded, in the concentrations testifies, $50 \mathrm{mg} \mathrm{L}^{-1}$ and $100 \mathrm{mg} \mathrm{L}^{-1}$, with immersion of $3 \mathrm{~cm}$ of the base of the props in the solution, for 24 hours. More three treatments had been carried through
\end{abstract}

Cultura Agronômica, Ilha Solteira, v.24, n.2, p.215-224, 2015 
whose plantation was in the day of collection, making up of 12 treatments. The installation of the experiment was made in the month of November of 2003 and lead until January of 2004, being that the experimental delineation adopted was of blocks to perhaps, with 3 repetitions of 20 props for parcel. After 60 days, evaluated it percentage of surviving and taken root props, the number of leaf and sprouts for prop, had been evaluated it, as well as dry substance of roots and aerial part. In the conditions where the work was carried through, it was verified that: The rooting of prop sub-hand was superior to the types hand and lateral hand, having presented bigger values of rooting percentages $(96,67 \%)$, leaf survival, number, mass of dry substance of the roots and the aerial part.

Key words: Punica granatum L. Propagation for rooted. Indole-3-butyric acid.

\section{INTRODUÇÃO}

A romãzeira é propagada comercialmente através de sementes, há relatos de que pode ser propagada também vegetativamente através de estaquia e alporquia.

Na propagação por sementes as mudas desenvolvem-se inicialmente de forma lenta, bem como dão origem a plantas distintas, sendo que algumas produzem mais que outras plantadas sobre o mesmo solo, os frutos também são desiguais quanto a sua forma, tamanhos e isso provavelmente devida à segregação gênica.

As árvores frutíferas, em geral, são propagadas por via sexuada ou gâmica (por sementes) e por via assexuada ou agâmica. Dentre os métodos de propagação, o método assexuado ou agâmico, tem sido o mais utilizado entre as culturas, pois proporciona a uniformidade dos pomares, atribuída aos fatores genéticos das plantas que não são perdidos, destacando-se dentre os mais utilizados a enxertia, alporquia, mergulhia e estaquia (SILVA, 2004).

Assim, a propagação por estaquia poderá vir a ser um método de propagação de grande importância para a cultura. É um método amplamente utilizado pelos fruticultores e viveiristas, principalmente por ser um método prático simples e econômico.

O objetivo do presente trabalho foi verificar os efeitos do ácido endolbutírico no enraizamento de diferentes tipos de estacas de romãzeira, sob nebulização intermitente.

\section{MATERIAL E MÉTODOS}

O experimento foi conduzido sob um viveiro com $50 \%$ de redução de luz na Fazenda de Ensino Pesquisa e Extensão da UNESP Campus de Ilha Solteira, SP, situada a $20^{\circ} 22^{\prime}$ de latitude sul, $51^{\circ} 22^{\prime}$ longitude oeste e altitude de 335 metros, localizada no município de Selvíria-MS. O clima da região é do tipo AW conforme classificação de Koppen, apresentando precipitação anual média de $1330 \mathrm{~mm}$ e temperatura média anual de $25^{\circ} \mathrm{C}$ (CENTURION, 1982).

Cultura Agronômica, Ilha Solteira, v.24, n.2, p.215-224, 2015 
Foram utilizadas estacas de romãzeiras, com $15 \mathrm{~cm}$ de comprimento, retiradas do ponteiro, do sub-ponteiro e ponteiro lateral da planta matriz com 5 anos de idade. As estacas de romãzeira foram retiradas no dia 11/11/03, pela manhã e parte delas foram plantadas no mesmo dia, uma outra parte foi preparada e colocada em tratamento com acido indolbutírico em duas concentrações (testemunha, $50 \mathrm{mg} \mathrm{L}^{-1}$ e $100 \mathrm{mg} \mathrm{L}^{-1}$ ) ficando as bases $(3 \mathrm{~cm})$ mergulhadas na solução aquosa por 24 horas. No entanto, as estacas testemunhas sem AIB permaneceram com a base mergulhada em água por 24 horas.

As estacas foram colocadas no substrato a uma profundidade de aproximadamente 1/3 de seu comprimento. Foram utilizadas caixas plásticas com dimensões de 45x20x15 cm, contendo como substrato vermiculita média expandida.

O experimento foi conduzido sob nebulização intermitente, tendo sido utilizado aspersão por 7 segundos a cada 10 minutos. O intervalo foi determinado de modo a manter uma fina camada de água sobre a superfície das folhas no momento de maior evapotranspiração sem, no entanto, causar escorrimento. O sistema de nebulização era acionado por meio de um temporizador (“Timer").

Os tratamentos utilizados foram: 1) Estaca ponteiro, com plantio no dia da coleta. 2) Estaca ponteiro lateral, com plantio no dia da coleta. 3) Estaca sub-ponteiro, com plantio no dia da coleta. 4) Estaca ponteiro; 24 horas em água, antes do plantio. 5) Estaca ponteiro lateral; 24 horas em água, antes do plantio. 6) Estaca sub-ponteiro; 24 horas em água, antes do plantio. 7) Estaca ponteiro; 24 horas em $50 \mathrm{mg} \mathrm{L}^{-1}$ de AIB, antes do plantio. 8) Estaca ponteiro lateral; 24 horas em $50 \mathrm{mg} \mathrm{L}^{-1}$ de AIB, antes do plantio. 9) Estaca sub-ponteiro; 24 horas em $50 \mathrm{mg} \mathrm{L}^{-1}$ de AIB, antes do plantio. 10) Estaca ponteiro 24 horas em $100 \mathrm{mg} \mathrm{L}^{-1}$ de AIB, antes do plantio. 11) Estaca ponteiro lateral; 24 horas em $100 \mathrm{mg} \mathrm{L}^{-1}$ de AIB, antes do plantio. 12) Estaca sub-ponteiro; 24 horas em $100 \mathrm{mg} \mathrm{L}^{-1}$ de AIB, antes do plantio.

Durante a condução do experimento foram realizadas as seguintes avaliações, a cada 10 dias: Porcentagem de estacas sobreviventes; Porcentagem de estacas sobreviventes com raízes; Número médio de folhas por estaca sobrevivente; Número médio de brotos por estaca.

Aos 60 dias após o plantio das estacas, o experimento foi colhido, tendo sido retiradas às estacas do substrato, lavadas as raízes, e separado raízes e parte aérea.

Devidamente identificados foram colocados em sacos de papel e mantidos em estufa de circulação forçada de ar a $75^{\circ} \mathrm{C}$ até peso constante. Nesse momento foram realizadas as pesagens, e obtidas: Massa da matéria seca das raízes; Massa da matéria seca da parte aérea por estaca sobrevivente;

Foram consideradas estacas sobreviventes àquelas que se apresentavam com a parte aérea verde. Foram consideradas estacas enraizadas aquelas que não estavam secas ou apodrecidas e apresentavam raízes.

Foi utilizado o delineamento estatístico em blocos ao acaso, com 12 tratamentos, 3 repetições e 20 estacas por parcela. Utilizou-se comparações de médias pelo Teste de Duncan.

Cultura Agronômica, Ilha Solteira, v.24, n.2, p.215-224, 2015 


\section{RESULTADOS E DISCUSSÃO}

Na Tabela 1 encontram-se os valores referentes porcentagem de estacas sobreviventes, porcentagem de estacas sobreviventes com raízes, número médio de folhas por estaca sobrevivente, massa da matéria seca das raízes, massa da matéria seca da parte aérea por estaca sobrevivente e número médio de brotos por estaca.

\section{Porcentagem de estacas sobreviventes}

Os tratamentos 3 e 5 proporcionaram a maior porcentagem de estacas sobreviventes porem não diferiram estatisticamente dos tratamentos $2,4,6,9,10,11,12$, porém diferindose dos demais tratamentos.

A análise da comparação entre grupos de tratamentos revela que a maior porcentagem de sobrevivência de estacas foi obtida com estacas sub-ponteiros, que não diferiu do ponteiro lateral, porem diferiu do ponteiro. A diferença entre os valores demonstra que partes de um mesmo ramo podem apresentar distinto potencial de enraizamento, devido, provavelmente, às variações na composição química dos tecidos ao longo do ramo (HARTMANN; KESTER, 1975; FACHINELLO et al.,1994).

Constata-se também que, plantar no mesmo dia ou deixar para o dia seguinte não alterou a porcentagem de estacas sobreviventes. Quando comparado plantio sem e com AIB, também não houve diferença estatística significativa, porem quando comparado 24 horas em água com tratadas com AIB, houve diferença, mostrando redução na porcentagem de estacas sobreviventes quando aplicado AIB. Tal fato pode estar ligado à ausência de substancias inibidoras do enraizamento e da presença de hormônios em quantidades adequadas

\section{Porcentagem de estacas sobreviventes com raízes}

Verifica-se que houve diferença estatística significativa entre os tratamentos, sendo que o maior valor de porcentagem de estacas enraizadas $(96,67 \%)$ foi obtido no tratamento 5 porém diferiu dos tratamentos 1,7,8. Melgarejo et al. (2006), que verificaram que existem diferenças entre clones de romãzeiras quanto à porcentagem de estacas enraizadas, variando de 7,67 a $100,00 \%$.

Face ao exposto, fica evidente que para a romãzeira os melhores tipos de estacas quanto ao enraizamento são aquelas do tipo ponteiro lateral e sub-ponteiro, podendo o plantio ocorrer nas primeiras 24 horas após a coleta, não sendo necessário o uso de AIB. Tais resultados estão de acordo com Reuther et al. (1973) citados por Ono e Rodrigues (1996) que afirmam que as estacas de ponteiros, devem ser provenientes de ramos terminais de maturação recente. No presente trabalho contatou-se visualmente maior maturação nos sub-ponteiros e ponteiros laterais quando comparados com ponteiro. Segundo Hess (1969) citado por Ono e Rodrigues (1996). A formação de raízes adventícias em estacas depende de auxinas, carboidratos, etc., sendo que as auxinas influenciam diretamente a acumulação basal de carboidratos, bem como no aumento de sua concentração, condições que induzem ao enraizamento. 


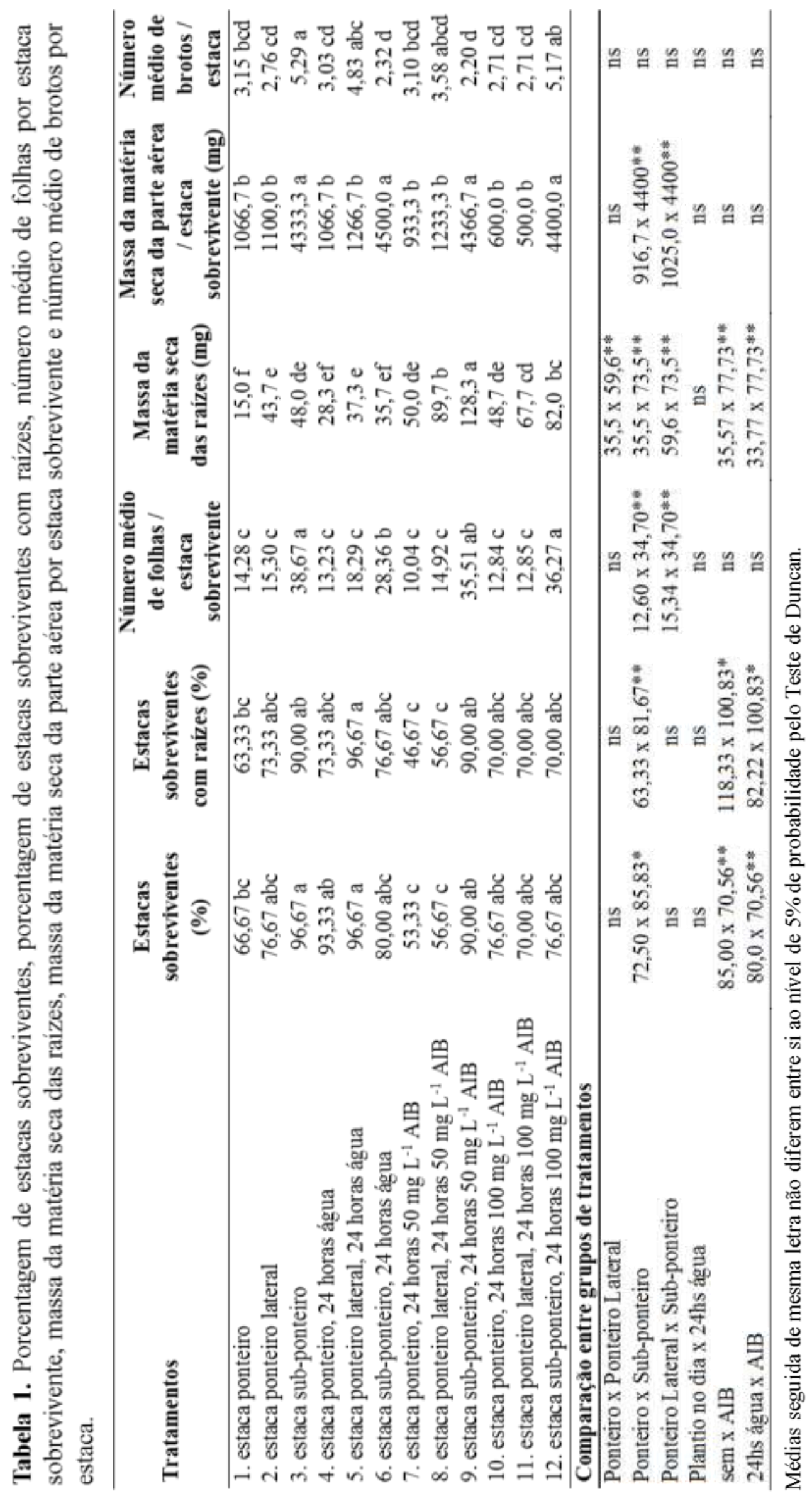

Cultura Agronômica, Ilha Solteira, v.24, n.2, p.215-224, 2015 
De acordo com Van Overbeek et al. (1946) e Lionakis (1981), citados por Ono e Rodrigues (1996), a presença das folhas garante a sobrevivência das estacas, tanto pela síntese de carboidratos através da fotossíntese, como pelo fornecimento de nutrientes, auxinas e outras substâncias, que são importantes no processo de formação das raízes, estimulando a atividade cambial e a diferenciação celular. No presente trabalho as estacas ponteiro lateral e sub-ponteiro apresentavam folhas mais maduras que as das estacas ponteiros, o que pode ter contribuído para a maior porcentagem de estacas com raízes, uma vez que maduras possuíam mais reservas.

A análise da comparação entre grupos de tratamentos revela que a maior porcentagem de estacas sobreviventes com raízes foi obtida com estacas sub-ponteiros, que não diferiu do ponteiro lateral, porem diferiu do ponteiro.

Constata-se também que houve diferença estatística significativa quando comparado o grupo sem AIB x com AIB e 24 horas em água x com AIB, o qual evidencia que houve efeito benéfico de AIB, aumentando a porcentagem de estacas enraizadas, somente para estacas mantidas em água por 24 horas.

As estacas sub-ponteiros no presente trabalho apresentavam maior diâmetro que as de ponteiro lateral, e nesse sentido Ribeiro e São José (1991), verificou em romãzeira, que estacas com 3,0 a 4,5 $\mathrm{mm}$ de diâmetro apresentaram melhor enraizamento do que estacas com 2,0 mm de diâmetro quando tratadas com AIB.

\section{Número médio de folhas por estaca sobrevivente}

Os tratamentos que apresentaram maior numero médio de folhas por estaca sobrevivente, foram os tratamentos 3 e 12, não diferindo estatisticamente do tratamento 9 , porém diferindo dos demais.

A comparação entre grupos de tratamentos, evidencia que as estacas tipo sub-ponteiro diferiu estatisticamente das estacas ponteiro e ponteiro lateral, tendo propiciado maior número de folhas por estaca. Dias et al. (1999) verificaram que estacas com maior diâmetro propiciaram formação de um maior número de folhas por estaca, o que pode ter ocorrido no presente trabalho uma vez que as estacas sub-ponteiro apresentavam maior diâmetro.

$\mathrm{Na}$ comparação entre os tratamentos das estacas plantio no dia x $24 \mathrm{hs}$ em água sobre o numero médio de folhas por estaca sobrevivente, não houve diferença estatística significativa pelo teste de Duncan. Tal resultado também ocorreu quando da comparação entre os grupos de tratamentos sem e com AIB, bem como 24hs em água x com AIB.

\section{Massa da matéria seca das raízes}

O tratamento que apresentou maior massa de matéria seca das raízes por estaca sobrevivente foi o tratamento 9, diferindo-se estatisticamente dos demais tratamentos.

A comparação entre grupos de tratamentos revela que quando comparados ponteiro $\mathrm{x}$ ponteiro lateral que houve diferença estatística significativa, sendo que as estacas de ponteiro lateral obtiveram uma maior massa da matéria seca das raízes. Da mesma forma ocorreu com estaca ponteiro x sub-ponteiro, bem como com ponteiro lateral x sub-ponteiro, 
sendo que o maior valor de massa da matéria seca das raízes foi obtido com estaca subponteiro, evidenciando ser este o melhor tipo de estaca com relação ao acúmulo de matéria seca.

De acordo com Tavares (1994), raízes com maior diâmetro são formadas em estacas da porção mediana dos ramos porque estas possuem maiores teores de substâncias de reserva do que as apicais, o que pode explicar o ocorrido no presente trabalho.

Ainda na comparação entre grupos de tratamentos, verifica-se diferença estatística significativa quando se compara sem x com AIB, sendo que o uso do AIB proporcionou maior acumulo de matéria seca. Da mesma forma ocorreu na comparação entre $24 \mathrm{hs} \mathrm{em}$ água x com AIB, evidenciando mais uma vez que o AIB aumenta a produção de matéria seca das raízes. Resultado semelhante foi encontrado por Manfroi et al. (1997) em estacas de Actinidia deliciosa, onde à medida que aumentou a concentração de AIB, elevou-se a matéria seca das raízes, mostrando que o uso de AIB contribuiu efetivamente para o aumento do sistema radicular.

\section{Massa da matéria seca da parte aérea por estaca sobrevivente}

A análise revela que houve diferença estatística significativa entre os tratamentos, sendo que a maior massa de matéria seca da parte aérea por estaca sobrevivente foi obtida nos tratamentos 3, 6, 9 e 12 , os quais diferiram estatisticamente dos demais.

$\mathrm{Na}$ comparação entre grupos de tratamentos, para as estacas ponteiro x ponteiro lateral não houve diferença estatística significativa.

Comparando os grupos de tratamentos de estacas ponteiro x sub-ponteiro, nota-se que houve diferença estatística significativa.

$\mathrm{Na}$ comparação entre os grupos de tratamentos de estacas ponteiro lateral $\mathrm{x}$ subponteiro, verifica-se que houve diferença estatística. Ao se comparar as medias nota-se que as estacas sub-ponteiros apresentaram valores superiores às estacas ponteiro lateral, evidenciando que as estacas sub-ponteiros são melhores.

Não houve diferença estatística significativa para comparação entre os seguintes grupos de tratamentos: plantio no dia x 24hs em água, sem AIB x com AIB e 24hs em água $\mathrm{x}$ com AIB.

\section{Número médio de brotos por estaca}

O tratamento que apresentou o maior número médio de brotos por estaca foi o 3 , não diferindo estatisticamente dos tratamentos $5,8,12$, porém diferindo dos demais tratamentos.

Quando comparados os grupos de tratamentos ponteiro x ponteiro lateral, nota-se que não houve diferença estatística significativa, o mesmo ocorreu quando foram comparados os seguintes grupos de tratamentos: ponteiro x sub-ponteiro, ponteiro lateral x sub-ponteiro, plantio no dia x 24hs água, sem AIB x com AIB e 24hs água x AIB.

Cultura Agronômica, Ilha Solteira, v.24, n.2, p.215-224, 2015 


\section{CONCLUSÕES}

Com base nos resultados obtidos nas condições do presente trabalho, pode-se concluir que:

a) $\mathrm{O}$ enraizamento de estaca sub-ponteiro foi superior aos tipos ponteiro e ponteiro lateral, tendo apresentado maiores valores de porcentagens de enraizamento (96,67\%), sobrevivência, número de folhas, massa de matéria seca das raízes e da parte aérea.

b) O uso do ácido indolbutírico propiciou somente o aumento na porcentagem de massa da matéria seca das raízes, porém reduziu a porcentagem de estacas com raízes, bem como porcentagem de estacas sobreviventes. O ocorrido se explica pelo fato do AIB ser uma auxina e atuar diretamente nas raízes.

A permanência das estacas por 24 horas em água não teve efeito sobre as características em relação às plantadas no mesmo dia.

\section{REFERÊNCIAS BIBLIOGRÁFICAS}

CENTURION, J. F. Balanço hídrico na região de Ilha Solteira. Científica, Jaboticabal, v. 10, n. 1, p.57-61, 1982.

DIAS, R. S. L.; FRANCO, E. T. H.; DIAS, C. A. Enraizamento de estacas de diferentes diâmetros em Platanus acerifolia (Aiton) Willdenow. Ciência Florestal, Santa Maria, v. 9, n. 2, p.127-136, 1999. Disponível em: <http://www.ufsm.br/cienciaflorestal/artigos /v9n2/art11v9n2.pdf>. Acesso em: 23 mai. 2006.

FACHINELlO, J. C.; HOFFMANN, A.; NACHTIGAL, J. C.; KERSTEN, E.; FORTES, G. R. L. Propagação de plantas frutíferas de clima temperado. Pelotas: UFPEL, 1994. 179 p.

HARTMANN, H. T.; KESTER, D. E. Plant propagation. New Jersey: Prentice-Hall, 1975. $662 \mathrm{p}$.

MANFROI, V.; FRANCISCONI, A. H. D.; BARRADAS, C. I. N.; SEIBERT, E. Efeito do AIB sobre o enraizamento e desenvolvimento de estacas de kiwi (Actinidia deliciosa). Ciência Rural, Santa Maria, v. 27, n. 1, p.43-46, 1997.

MELGAREJO, P.; MARTÍNEZ, J.; MARTíNEZ, J. J.; VALERO, R. M.; AMORÓS, A. Study of the rooting capacity of eleven pomegranate (Punica granatum L.) clones, using plastic to cover the soil. Advances in research and technology, Zaragoza, v. 42, p.169173, 2000. Disponível em: 〈http://www.ressources.ciheam.org/om/pdf/a42/00600267.pdf〉. Acesso em: 22 mai. 2006.

Cultura Agronômica, Ilha Solteira, v.24, n.2, p.215-224, 2015 
ONO, E. O., RODRIGUES, J. D. Aspectos da fisiologia do enraizamento de estacas caulinares Jaboticabal: FUNEP, 1996. 83 p.

RIBEIRO, A. A.; SÃO JOSÉ, A. R. Efeitos do fitohormônio IBA no enraizamento de estacas de romãzeira. Revista Brasileira de Fruticultura, Cruz das Almas, v. 13, n. 1, p.157-159, 1991.

SILVA, C. P. Efeito do ácido naftalenoacético e ácido indolbutírico no enraizamento de estacas de aceroleira (Malpighia emarginata DC.) pinheira (Annona squamosa L.) e gravioleira (Annona muricata L.), sob nebulização intermitente. 2004. 100 f. Dissertação (Mestrado em Agronomia) - Faculdade de Engenharia de Ilha Solteira, Universidade Estadual Paulista “Julio Mesquita Filho", Ilha Solteira, 2004.

TAVARES, M. S. W. Propagação da goiabeira (Psidium guajava L.) através de estacas. 1994. 66 f. Dissertação (Mestrado em Agronomia) - Universidade Federal de Pelotas, Pelotas, 1994. 
